SCHOLARS: Journal of Arts \& Humanities

[Peer-Reviewed, Open Access Scholarly Publication] Indexed in NepJOL; JPPS Star-Ranked Journal

Print ISSN: 2773-7829; e-ISSN: 2773-7837

eJournal Site: www.cdetu.edu.np/ejournal/
Central Department of English

Tribhuvan University

Kirtipur, Kathmandu, Nepal

URL: www.cdetu.edu.np

Theoretical/Critical Essay Article

\title{
The Politics of Body in Bhisham Sahni's Madhavi: Rethinking the Mythical Performance
}

\author{
Yog Raj Lamichhane
}

School of Business, Pokhara University, Nepal

Article History: Submitted 15 May 2021; Revised 2 July 2021; Accepted 5 August 2021

Corresponding Author: Yog Raj Lamichhane,Email: lcyograj@pu.edu.np

DOI: https://doi.org/10.3126/sjah.v3i2.39428

Copyright 2021 (C) The Author(s). The work is licensed under a Creative Commons Attribution 4.0 International License (CC BY 4.0).

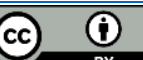

\begin{abstract}
Madhavi, a blessed body with eternal virginity, is the central character of Bhisham Sahni's play Madhavi. This paper attempts to explore her boon of eternal virginity as a patriarchal scar inscribed by the society on her womb. How do her ultimate rejection of that scar and the final journey to actual eternity become the insightful performances to respond to the societal body politics? This is the major concern of the study. In this interpretation, mainly the concepts of Michel Foucault and Judith Butler regarding the body politics and the notions of Jennifer Parker-Starbuck, Roberta Mock, and Richard Schechner concerning the body and its performance are synthesized as a theoretical framework to analyze the textual evidence and to observe the performance of the politically conditioned, condemned and trivialized body of Madhavi. Finally, the study ascertains that the perpetually subordinated body gradually comprehends the society and insightfully performs liberty against the hegemonic power bloc. In the play, the proactive proposal of Madhavi to Vishwamitra for lovemaking and her ultimate disappearance into nature in search of actual eternity can be a leading evidence of the insightful performances towards liberty.
\end{abstract}

Keywords: Body politics, condemned body, performance, resistance, sexuality, eternal virginity, virgin eternity

\section{Introduction}

When an engagement of a woman with saggy breasts and a wrinkled face is about to be performed, what would the virtuous woman do if she deserves the boon of 'eternal virginity'?

To respond to it, Bhisham Sahni rewrites the ancient myth from the Mahabharata in the form of the play Madhavi. It exhibits how the blessed body of the

\footnotetext{
${ }^{1}$ According to the Mahabharata and the play Madhavi, Madhavi can restore her beauty and virginity because of the boon of eternal virginity. Mary also deserves such perpetual virginity even after the birth of Jesus as explained in biblical texts.
} 
central character Madhavi performs freedom against religion, culture, and politics, and internalizes the meaninglessness of the eternal virginity and significance of the virgin eternity. She vanishes from the stage in a crucial time of her engagement discarding her own blessed body. In this regard, the study aims to establish eternal virginity as a patriarchal scar inscribed by society on her womb. Moreover, it examines her ultimate rejection of that scar and the final journey to actual eternity as insightful performances to resist the dominant body politics of the culture and society.

The classical society teaches Madhavi that the duties concerning parents, dharma, and guru as the highest virtues in one's life. In the play, King Yayati, Madhavi's father and one of the regulators of such ideology, offers his obedient daughter to Galav suggesting to negotiate her beauty and virginity with different kings for eight hundred Ashwamedha ${ }^{2}$ horses. As promised, Galav is in search of these horses to pay off his debt to guru Vishwamitra for imparting knowledge before his installation ceremony. Then, Madhavi is enforced to perform as a machine to manufacture the sovereign sons for the kings without getting any opportunity to enjoy motherhood. Madhavi's journey of giving birth to sovereign sons with the different kings seems directly proportional to her perpetual missing of motherhood. The boon of the eternal virginity of Madhavi turns to be a curse later when her body is continuously politicized in terms of sexuality.

Nevertheless, Galav enjoys collecting the horses by renting her fertile womb. After sleeping with three kings and managing six hundred horses, her body exhausts. Again, recollecting vigor, Madhavi approaches Visawamitra and boldly invites him to sleep with her at the cost of deducing two hundred horses from the demand list of eight hundred. Vishwamitra accepts her proposal. Finally, Galav fulfills his promise, but no one cares about Madhavi and her desire.

In this context, rather than analyzing the plain role of Madhavi in the play, the paper analyzes her body as a site of politics, discipline, and resistance. On the terrible condition of the body, Jennifer Parker-Starbuck and Roberta Mock assert:

Bodies are the material through which theatre researchers most often discuss performance; they are scrutinized, critiqued, displayed, transformed, gendered, controlled, and determined in critical reviews, historical accounts, and theorizations of practices such as theatre, live art, and dance. (210)

Considering the body as a site of performance, they appear to establish it as an area of research. In this regard, body and body politics remain at the center of performance studies.

Moreover, for this qualitative interpretation, mainly the concepts of Michael Foucault's writings on 'The Body of the Condemned' and 'The History of Sexuality' and Judith Butler's ideas regarding 'Undoing Gender' and 'Bodies that Matter' along with the notions of Richard Schechner's 'Fundamentals of Performance Studies' concerning a body and its performances are synthesized as a theoretical framework to analyze the textual evidence and observe the role of the politically conditioned, condemned and trivialized body of Madhavi. It is not directly coercive, but her body is hegemonized to play such a role by patriarchy. Ultimately, she happens to realize the subjugation and begins to love her own saggy and wrinkled body, rejecting and resisting the suggestions of Galav to reassume her virginity and beauty. Then, her body neither appears on the stage of the installation ceremony of Galav nor accepts to be a part of the engagement program. Rather, she "rejects the society that negates her being, refusing to be exploited

\footnotetext{
${ }^{2}$ Ashwamedha is a kind of flawless white horse that gives a sense of sovereignty to the kings and warriors. It is also used to perform the religious sacrifice. The Indian epic Mahabharata thoroughly explains its story.
} 
anymore" (Singh 172). The insightful learning and resisting performance strengthen her politicized body to initiate the journey to freedom.

The politicized bodies can free themselves by non-performing the script of the hegemonic power bloc in the form of self-agency. To free oneself from such political prison and cultural chain, the body of Madhavi involves in proactively appearing in front of Vishwamitra proposing him for lovemaking and vigorously disappearing from society discarding virgin eternity. Her body as a historicist tells the contemporary narratives of society and stands as a microcosm of social revolt. Regarding the role of the body in Performance Studies, Parker-Starbuck and Mock consider, "bodies 'as' the locus of performance as they are in researching bodies 'in' performance" (210). Therefore, both 'body as performance' and 'body in performance' are to be understood to realize the societal body politics and resistance of Madhavi. To do so, the body, behavior, and activities of Madhavi are the most powerful evidence for the study of her paradoxical performance, which finally leads her to insightful resistance and liberty.

\section{Review of Literature}

Multiple studies have interpreted the text, Madhavi, by applying different theories and perspectives like commoditization, instrumentalization, deconstruction, trauma and resistance.

In the modern era, many publications have appeared rewriting ancient subjects in a contemporary pattern. Commenting on this culture, Guru Charan Behera identifies Bhisham Sahni as a facilitator of feminist strategy who forms a novel myth deconstructing the old one by repositioning and resituating the status of women at present (180). It dismantles the fixed gender hierarchy and enforces to rethink the classical perception of society towards women.

The patriarchal society commonly objectifies the female body. In this regard, Oindri Roy assesses how the society has understood Madhavi, the protagonist of the play Madhavi, as an object, "when her body is put to scrutiny by kings and their aides to judge her sexual prowess or her auspiciousness to be deemed suitable for bringing an heir to the throne" (161). In this culture and context, the heir resembles the son and the throne represents power. Imposing the same power, the kings take Madhavi as a miraculous tool to invent the brave rulers. She becomes an industry regulated by power politics. Roy further interprets her final decision to leave society as the expression of her traumatic experience (161). The trauma might be triggered by the perpetual social injustice that assumes women just as machines.

Soham Patel expands the earlier observation of Roy in a research report entitled "The Daughter Industry"; which has found Madhavi as a "messenger essentially with the duty to get the men in the play the glory they feel is entitled to them" (1). It encourages the practice of sex preference. Madhavi, as a human, has nothing to do for her sake in such a role. She is automated like an instrument, which has to work silently for other owners.

Madhavi is also studied as an interplay between hegemony and resistance. Kiran Budkuley identifies sex, politics, and philosophy as hegemonic weapons used by the 'arbitrators' of a dominant group in manipulating female consent, and presents Madhavi, not only as an emblem of persecution but also as a symbol of resistance (25). Then, Madhavi abandons the imposed role as a childbearing engine and becomes a resisting hero. Ultimately, that becomes the "story of its resistance against patriarchal control" (Nandy 54). Bhisham Sahni has skillfully dramatized the story inspiring his readers to be resisting heroes. 
Resisting involves in advocating the marginal and muted voices. Pankaj K. Singh and Jaidev have suggested a roadmap for decentering and resisting such patriarchal hegemony by welcoming the 'abused' and 'invisible' victim in the forefront for speaking, feeling, and protesting (4). The roadmap of resistance seems to focus on developing self-agency rather than giving agency from outside.

The existing literature has raised the issues of the commoditization of the female body to generate surplus considering the traumatized women as childbearing industry and declared about the birth of resistance hero in Madhavi. The text has also been observed as deconstructing ancient myths. However, this study assesses the eternal beauty of Madhavi as the scar inscribed by patriarchy on her body and womb, and her final resisting breakthrough as insightful performance to respond the societal body politics. Moreover, it clearifies how the non-performance of the script of hegemonic power bloc in the form of self-agency guides such a politicized body to liberty.

\section{Methodology}

English version of Bhisham Sahni's play Madhavi recounts the ancient tale of the Mahabharata. Alok Bhalla had translated it into English from Hindi and it was purposively selected for the study. On the popularity and significance of retailing myth and mythical characters, Sabita Mishra writes, "Retelling of Indian epics and mythical characters have gained popularity out of literary circulation and story-telling that continues to generate literary responses from research scholars" (165). In this research too, the text was selected because of its legacy to ancient myth, its transformation in modern form, and its readership at present.

The study followed the interpretive paradigm in terms of philosophical assumptions. The interpretive paradigm attends to "participants' feelings and intuitions in ways that make values part of the research investigations" (Putnam and Banghart 5). It believes that the truth resides in individual ideas and interpretation can reveal it out. Interpretivism believes, the "perceptions of reality are constituted as subjects attach meaning to phenomena and that these meanings arise through interactions" (Zoller and Klineour 93). According to it, knowledge can be acquired by understanding and interpreting the social environment. To understand and interpret the evidence from the selected text, this study involved in textual analysis method. It further engaged in identifying the textual evidence and constructing meaning.

The theoretical framework chosen for this study ascertained the area for such identification and interpretation. Michael Foucault's writings on 'The Body of the Condemned' and 'The History of Sexuality', Judith Butler's ideas regarding 'Undoing Gender' and 'Bodies that Matter', Jennifer Parker-Starbuck and Roberta Mock's concepts on 'Body in/as Performance', and Richard Schechner's insights on 'Fundamentals of Performance Studies' were applied as the theoretical framework. The framework was used to observe and analyze the body and behavior of the characters from the play, mainly the performance of the politically conditioned, condemned, and trivialized body of Madhavi.

\section{Eternal Virginity to Virgin Eternity}

Who comes to rescue the dignity of a daughter, when her father involves in politicizing the sexuality of the daughter?

Yayati, an arrogant father of Madhavi, considers the body of his daughter as his property and offers 'it' to Galav as a gift, suggesting to exchange with eight hundred Ashwamedha horses. He performs the role of an owner to market her body in terms of sexuality that the sons born from her womb shall turn into sovereign emperors. Madhavi 
surprisingly stares at her father with confusion and later asks, "If the mother were alive, would she have let you gift me away like this" (Sahni 10)? She covertly questions patriarchy against the transfer. However, she cannot protest the materialization of her sexuality. Like Yayati, rather than respecting her dignity, Galav treats her just as a collection of the blessed bone and flesh. Her body is politicized constructing hierarchies like "masculine/feminine; mind/body; able-bodied/disabled; fat/skinny; heterosexual/ homosexual; and young/old" (Brown and Gershon 1). Madhavi represents a similar subordinated side of the dichotomy. Michel Foucault projects the tameness of the body referring to history. Foucault reminds, "The body had become the object of such imperious and pressing investments; in every society, the body was in the grip of stringent powers, which imposed on its constraints, prohibitions or obligations" ("Discipline" 136). There is a history that the body is targeted and controlled as objects by the authorities manipulating the consent of the marginalized one.

In body politics, the marginalization of sexuality resides at the center. In the play, beyond the physicality of Madhavi's body, different authoritarian norms are applied to condition her sexuality for achieving materialization. Beyond physicality, body politics regulates "'sex' and achieves this materialization through a forcible reiteration of those norms" (Butler, "Bodies" 236) using power, religion, and culture. It emphasizes the performativity of the body rather than the simple role-playing. Butler further defines performativity as a 'reiterative' and 'citational' practice which "constitutes the materiality of bodies and, more specifically, to materialize the body's sex" (236). In the study of body politics, performativity concentrates on the body, especially in the body's sex. Similarly, the body of Madhavi is believed in society to be performed as an object of a barter system, and her boon of eternal virginity supports such performance. Gender and performance are organically connected concepts. "Gender identity is a performative accomplishment compelled by social sanction and taboo. In its very character as performative resides the possibility of contesting its reified status" (Bulter "Performative Acts" 520). The culture of social endorsement and prescription forces the body to follow the guidelines of authority.

Silence and smile turn into 'weaknesses' of the female body. Madhavi, with a faint smile, accepts herself as a means to fulfill the desires of the kings. As a political unit, her body endures cultural forces. Michel Foucault explains about such politicization, where society and culture enforce such bodies to carry out subjugated rituals beyond the biological process referring to discipline for possible investment, preparation, and pain ("Discipline" 25). Madhavi accepts, "I am only an instrument- a means to an end for you, today, and for some other king, tomorrow" (Sahni14). It is the societal body politics, where "the body itself is politically inscribed and is shaped by practices of containment and control" (Browna and Gershonb 1). Rather than accommodating her own life with intrinsic value, she implements the politics as directed by patriarchy, mainly by her father, Galav, and the kings. She admits to give birth to sovereign sons without claiming the opportunity to enjoy motherhood. There, she lacks an economic and political understanding of the body; she is only being dependent on destiny and duty as taught earlier.

Madhavi deserves no dignity as her father offers her to a stranger for exploiting sexuality. To do so, in the process of negotiating her body to King Haryashch from Ayodhya, who questions her coyness telling, "Woman who has been given away as a gift can't afford to have any pride. You are here as a beggar" (Sahni 18). He challenges her being inferiorizing her body. Regarding the inequality, Veronique Mottier clears, "women's sexuality was conceptualized as a response to male desire" (34). Hence, male does not care about the dignity of female body and appears busy in subordinating and 
subjugating it. To verify the qualities of Madhavi's body for the potential business, the king calls the royal astrologer to examine the different parts of her body. He enumerates the signs by pointing the body parts with a stick (Sahni 20). Muted Madhavi surrenders her body to "extort its forces, increase its usefulness and docility, integrate it into systems of efficient and economic controls" (Foucault, "The History"139). Madhavi performs passivity in this whole process where her parts of the body are being estimated for the final commoditization of her womb. Not everyone can play such a gender role intentionally. "One is always, Judith Butler writes, 'doing' with or for other even if the other is only imaginary" ("Undoing Gender" 1). Gender is purely performance for Butler. Gender as an enactment contributes to shaping a body. Angela King comments on the linkage of gender to femininity and explains how there is an order that constructs the body and functions as an efficient form of communal control (29). Such a controlling mechanism always orients to the submissive bodies of women.

Culture is a prime factor to mold the role of a body. It works as a "mode of dramatizing or enacting possibilities offers a way to understand how a cultural convention is embodied and enacted" (Butler, "Performative Acts"525). To perform such enacted role of cultural politics, she appears in the palace. There, she shares to Galav, "I feel that I am being taken to a dungeon instead of a palace ... but all this will soon pass ... I shall count each day, Galav ... Who knows when we'll meet again! ... Take care of yourself ... and don't worry about me ... remember me ... don't forget me" (Sahni 24). What do these dots mean? The performance of her subjectivity is hurdled by obstructions. The language could never detect and express these reflections. It can be clarified only by performance. In the words of Richard Schechner, performance study, as behavioral science, stresses "activity rather than a book or the archive" ("Fundamentals" xi). To comprehend the above painful situation, the audience has to participate in the performance and infer from the 'doing' rather than decoding script. The gaps are also significant along with the signs.

Not all mothers get the opportunity to enjoy motherhood equally. After giving birth to the first son with a king, Madhavi knows from a servant girl that the priest has named the child, Vasumana. At that moment, she only kisses him, whispering the name. Who has stopped her to pronounce the name of 'her' infant child? It resembles biopolitics, in the words of Roberta Sassatelli, which reduces "the subject to the body and the body to the possessive text" (350). Realizing so, Madhavi opposes the suggestion of a servant to stay in Ayodhya anymore and says, "No, I am not his mother. I am only someone who has given birth to him. That's all" (Sahni 31). Differently at the same time, her contradictious body claims Vasumana as her son. However, Galav advises her not to be sentimental, threatening her motherhood. She realizes that she is no more than a body, the mechanized body that has to perform for producing a child rather than being an actual mother.

The palaces change but Madhavi finds the nature of the kings alike. Again, she has to exhibit her body to justify her competency concerning lovemaking. Madhavi and Galav approach the lusty King Devodas from Kashi. Without any hesitation, he asks her, whether she knows about sex or not (Sahni 41). Madhavi does not react. Calling her a terrible girl with dirty clothes, Devodas examines her body through a "controlling gaze" (Pylypa 22) as a customer of the sex market. Judith Butler relates such performance, which is analogous to the performance of the gendered body, which follows the fixed commandments ("Performative Acts" 525). Devodas becomes the father of a brave son with the support of Madhavi, though he has already seventeen daughters from the queens. It is the process, how the thrust of a son is ritualized in society. 
The auction of Madhavi's body does not stop there because she is conditioned to perform on multiple patriarchal stages. After offering two sons to two kings and managing four hundred horses respectively, Galav and Madhvi reach Bhojnagar. They stand before King Ushinar's palace. Without asking for any consent, "the old king puts a garland around her neck and marries her" (Sahni 49). He trims her subjectivity and identity. Regarding the situation, Michel Foucault emphasizes that the king's body with a certain degree of authority manipulates power to subordinate other ("Discipline" 208).

Similarly, the possession of Madhavi is transferred to King Ushinar as a matter, and the body gives birth to a son. Again, she fails to enjoy motherhood, even after giving birth to three sons. It is the outcome of the historical reiteration. The societal custom, culture, and convention have actively served to dramatize anybody as a historical body. So, a body can be described as a "historical situation, as Beauvoir has claimed, and is a manner of doing, dramatizing, and reproducing a historical situation" (Butler, "Performative Acts" 521). It resembles the reiteration process of history and sexuality concerning the female body.

The patriarchal society has not completed the journey of exploiting Madhavi's body yet. Still, Galav has to manage the last slot of two hundred horses exploiting her body. Galav as an operator of this system performs "to discipline the body, optimize its capabilities, extort its forces, increase its usefulness and docility, integrate it into systems of efficient and economic controls" (Foucault, "The History"139), molding the body in the desired shape. This time, Madhavi seems to perform with boldness. Nevertheless, the body has not achieved any freedom yet. After that, suddenly, her body disappears. Galav feels a void, as he has missed the absolute performer for collecting the remaining horses. Madhavi surprisingly appears in the ashram of Vishwamitra performing boldly. Astonishingly, she takes the role of a substantial body with confidence offering Vishwamitra to play with her body as the previous three kings have played. She keeps a condition to deduce the remaining number of horses for doing that (Sahni 55). Vishwamitra puts his arms on her body as acceptance and takes her inside his hut. Her proposal works there. This time, her body and action seem to perform different gender roles. To quote the words of Judith Butler, "gender reality is performative which means, quite simply, that it is real only to the extent that it is performed" ("Performative Acts" 527). To explicate the idea, in the words of Richard Schechner, performance involves the "repetition-of-the-never-the same" ("Fundamentals" iv). Exactly, Madhavi performs 'continuation' as well as 'breakthrough,' purely resembling the ephemeral nature of Performance Studies. Except the repetitive part of lovemaking, she performs confidence transforming her body and breaking the snobbery of Vishwamitra, who has asked for eight hundred horses to break the arrogance of Galav. Consequently, it seems that it is the continuation, which guides a performer to breakthrough offering experience and environment.

From the history of human civilization, some actual actors fail to get credit for their hard work. Here too, Madhavi has to labor and suffer, but credit goes to Galav. He fulfills his vow. Further, Yayati claims that Vishwamitra has tasted him, not Galav. Subsequently, he prepares two stages in his ashram for the installation of Galav and the engagement between Madhavi and Galav. There might be a covert consent of Galav. On the contrary, this time, there appears a different scene. Not as a woman who has a boon of eternal virginity, "Madhavi's breasts sag. Her face has lost its color and is wrinkled. There are dark circles under her eyes. She is dressed very ordinarily and looks like a middle-aged woman" (Sahni 63). She looks meditating upon herself. Correlating mindfulness, insights, and liberty, Laurie Hollis-Walker and Kenneth Colosimo borrow Buddhist psychology and speculate, "Mindfulness leads to insight into and liberation 
from suffering (226). In such a situation, one insightfully learns the lesson and meaning of life.

Some become intellectual attending formal courses, but many other become thinkers, going through the courses of life. Time becomes the teacher there. Madhavi comes in the second type of scholar. In the final conversation between Galav and Madhavi before participating in the installation ceremony, Galav insists on her to regain beauty and virginity. Representing such situations, Judith Butler has connected the idea of gender performativity to the materialization of sex, and emphasizes:

Sex is an ideal construct, which forcibly materialized through time. It is not a simple fact or static condition of a body, but a process whereby regulatory norms materialize sex and achieves this materialization through a forcible reiteration of those norms. That this reiteration is necessary is a sign that materialization is never quite complete, that bodies never quite comply with the norms by which their materialization is impelled. ("Bodies" 236)

Sex as an ideological construct applies in shaping and achieving materiality. Spectators have already acknowledged Galav and Madhavi's love for each other as they had shared with other characters. However, Galav opposes her in natural form, when she resists performing as a beautiful and virgin woman again. Galav, witching context to duty, tells Madhavi that he cannot marry a girl who has lived with his guru Vishwamitra. It reveals the strategies of male chauvinism that believes in materializing female sexuality.

Personal dignity matters in every relationship and it emerges at different turning points. In the case of Madhavi, she seems to feel about self-respect as society has been repeatedly politicizing her 'condemned body'. At this moment, she executes to free herself from 'bio-power', which considers the body as the spot of suppression and engages in coercion as people partake in their ritualized physical performance (Pylypa 22). Galav insists on Madhavi continuously suggesting to regain virginity and beauty, but she considers such restoration as deceiving oneself. Madhavi, being optimistic, claims, "The world is a vast place. I am sure that somewhere there will be room for me" (Sahni 68). She has already started to explore the appropriate space in the world. It is done mindfully. As described by Ellen Jane Langer, "When we are mindful, we are open to surprise, oriented in the present moment, sensitive to context, and above all, liberated from the tyranny of old mindsets" (qtd. in Tang 2). Similarly, to liberate herself, she immediately disappears from the vulnerable world. All these events make her active, independent, and competent.

Finally, she has proved through her insightful performance that eternal virginity is nothing more than a patriarchal scar for her and virgin eternity is the last resort of her life.

\section{Conclusion}

The study has mainly assessed the performance of a paradoxical body, which is a blessed body for patriarchal culture and society, but ultimately appears condemned throughout the analysis. The eternal virginity of Madhavi becomes a male chauvinistic scar inscribed by a power bloc on her womb. The insightful rejection of that scar fixes her final journey to actual eternity rejecting the societal body politics. Especially, the repetition of the subjugated role assigned to copulate with multiple kings stimulates her to liberate herself.

It is inferred from the analysis that such a politically trivialized body can free itself by non-performing the script of hegemonic power and politics. Madhavi's proactive proposal to Vishwamitra for lovemaking and her deliberate disappearance into nature in 
search of virgin eternity serve for the insightful performance that resists male chauvinism.

In terms of contemporary concern, the interpretation of the rewritten account of the Hindu myth contributes to the modern audience as a roadmap for insightful performance to release oneself resisting false tutelages incurred in any society and culture. Such rationalization specifically supports to counter male chauvinism that generally entraps women in the name of duty and discipline without any reward. A further comparative study of the female mythical characters from multiple cultures can make this rationalization stronger.

\section{Works Cited}

Behera, Guru C. "Deconstruction of Myth as Feminist Strategy: Bhisham Sahni's Madhavi." Middle Flight, vol. 6, no. 1, 2017, pp. 175-181, http://www.ssmahavidyalaya.org/uploadedfiles/news/50ecf372670dfa300c6f2cd 922b87cdf.pdf\#page $=187$.

Brown, Nadia, and Sarah A. Gershon. "Body politics." Politics, Groups, and Identities, vol. 5, no. 1, 2017, pp. 1-3, https://www.tandfonline.com/doi/full/10.1080/21565503.2016.1276022.

Budkuley, Kiran. "Mahabharata Myths in Contemporary Writing: Challenging Ideology." Myth in Contemporary Indian Literature, edited by K. Satchidanandan, Sahitya Academy, 2010, pp. 16-30, http://irgu.unigoa.ac.in/drs/handle/unigoa/3536.

Butler, Judith. Bodies that Matter: On the Discursive Limits of Sex. Routledge, 1993.

---. "Performative Acts and Gender Constitution: An Essay in Phenomenology and Feminist Theory." Theatre Journal, vol. 40, no. 4, 1988, pp. 519-31. JSTOR, https://www.jstor.org/stable/3207893.

---. Undoing Gender. Routledge, 2004.

Foucault, Michel. Discipline and Punish: The Birth of the Prison. Translated by Alan Sheridan, Vintage, 1977.

---. The History of Sexuality. Volume I: An Introduction. Translated by Robert Hurley, Vintage, 1980.

Hollis-Walker, Laurie, and Kenneth Colosimo. "Mindfulness, Self-Compassion, and Happiness in Non-Mediators: A Theoretical and Empirical Examination." Personality and Individual Differences, vol. 50, no. 2, 2011, pp. 222-27, https://www.jstor.org/10.1016/j.paid.2010.09.033.

King, Angela. "The Prisoner of Gender: Foucault and the Disciplining of the Female Body." Journal of International Women's Studies, vol. 5, no. 2, 2004, pp. 29-39, http://vc.bridgew.edu/jiws/vol5/iss2/4.

Mishra, Sabita. "A Modern Approach to Retelling of Indian Epics and Mythical Characters." International Journal of English Language, Literature and Translation Studies, vol. 6, no. 3, 2019, pp. 162-66, http://www.ijelr.in/6.3.19/162-166\%20Dr.\%20SABITA\%20MISHRA.pdf.

Mottier, Veronique. Sexuality: A Very Short Introduction. Oxford UP, 2008.

Nandy, Amrita. "Outliers of Motherhood: Incomplete Women or Fuller Humans?" Economic and Political Weekly, vol. 48, no. 44, 2013, pp. 5359. JSTOR, https://www.jstor.org/stable/23528807.

Oindri, Roy. "Transformative Corporality vis-à-vis Love in Mythological (Re) Telling: A Comparative Inquiry into Indian Revisionist Mythology." Art and Aesthetics of Modern Mythopoeia: Literatures, Myths and Revisionism, edited by Ashish K. Gupta and Ritushree Sengupta, Rudra Publishers and Distributors, 2020, pp. 
158-72, https://www.snapdeal.com/product/art-and-aesthetics-ofmodern/644130350250.

Parker-Starbuck, Jennifer, and Roberta Mock. "Researching the Body in/as

Performance." Research Methods in Theatre and Performance, edited by Baz Kershaw and Helen Nicholson, Edinburgh UP, 2011, pp. 210-35. JSTOR, https://www.jstor.org/stable/10.3366/j.ctt1g0b2vz.14.

Patel, Soham. The Daughter Industry. 2018. University of Wisconsin-Milwaukee, Ph.D.

Dissertation. UWM Digital Commons, https://dc.uwm.edu/etd/1893/.

Putnam, Linda L., and Scott Banghart. "Interpretive Approaches." The International Encyclopedia of Organizational Communication, edited by Craig R. Scott and Laurie Lewis, John Wiley and Sons, 2017, pp. 1-17, https://doi.org/10.1002/9781118955567.wbieoc118.

Pylypa, Jen. "Power and Bodily Practice: Applying the Work of Foucault to Anthropology of the Body." Arizona Anthropologist, no. 13, 1998, pp. 21-36, https://journals.uair.arizona.edu/index.php/arizanthro/article/view/18504/0.

Sahni, Bhishma. Madhavi. Translated by Alok Bhalla, Seagull, 2002.

Sassatelli, Roberta. "Body Politics." The Wiley-Blackwell Companion to Political Sociology, edited by Edwin Amenta, et al., Blackwell Publishing, 2012, pp. 34859, https://doi.org/10.1002/9780470696071.ch29.

Schechner, Richard. "Fundamentals of Performance Studies." Teaching Performance Studies, edited by Nathan Stucky and Cynthia Wimmer, Southern Illinois UP, 2002. pp. ix-xii, http://siupress.siu.edu/books/978-0-8093-8936-0.

---. "Rituals and Performance." Companion Encyclopedia of Anthropology, edited by Tim Ingold, Routledge, 1994, pp. 613-47, https://www.routledge.com/Companion-Encyclopedia-of-AnthropologyHumanity-Culture-and-Social-Life/Ingold/p/book/9780415286046.

Singh, Pankaj K. "Women's Writing in English New Voices." Indian Literature, vol. 39, no. 5, 1996, pp. 172-75. JSTOR, https://www.jstor.org/stable/24159218.

Singh, Pankaj K., and Jaidev. "Decentering a Patriarchal Myth: Bhisham Sahni's Madhavi." From Myths to Markets: Essays on Gender, edited by Kumkum Sangari and Uma Chakravarti, Indian Institute of Advanced Study, 1999, pp. 317, https://search.library.brown.edu/catalog/b3337872.

Tang, Yi-Yuan. The Neuroscience of Mindfulness Meditation. Palgrave Macmillan, 2017, https://doi.org/10.1007/978-3-319-46322-3.

Zoller, Heather M., and Kimberly N. Kline. "Theoretical Contributions of Interpretive and Critical Research in Health Communication." Annals of the International Communication Association, vol. 32, no. 1, 2008, pp. 89-135, https://doi.org/10.1080/23808985.2008.11679076. 